\title{
The Extractive Zone, Social Ecologies and Decolonial Perspectives, Macarena Gómez-Barris
}

\author{
Miguel Arrieta Villafuerte
}

Universidad Iberoamericana Ciudad de México

México

Latinoamérica ha sido considerada, desde el inicio de la empresa colonial en el siglo XVI, como un territorio de extracción. Aún en la actualidad, muchos países de este continente dependen económicamente de la industria petrolera y minera. La instalación de industrias de extracción sobre zonas habitadas por pueblos originarios, sumada a la contaminación y la violenta disminución de la biodiversidad genera una gran problemática para la región y el mundo. Macarena Gómez-Barris aborda esta compleja realidad en su libro The Extractive Zone ${ }^{1}$ (2017), en donde intenta aportar al análisis y la comprensión del capitalismo de extracción que avanza en Sudamérica, a través de una metodología

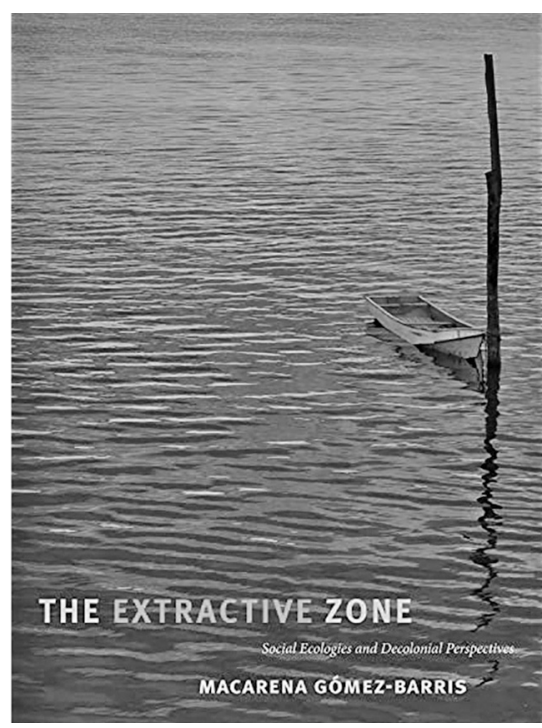

Macarena Gómez-Barris, The Extactive Zone. Social Ecologies and Decolonial Perspectives. Carolina del Norte: Duke University Press, 2017.

${ }^{1}$ Macarena Gómez-Barris, The Extactive Zone. Social Ecologies and Decolonial Perspectives (Carolina del Norte: Duke University Press, 2017). 
nutrida de las fuerzas vivas que resisten dentro de estos contextos.

Gómez-Barris es profesora y jefa del Departamento de Ciencias sociales y estudios culturales en el Pratt Institute en Brooklyn, Nueva York, también es directora del Global South Center (GSC). Ha dedicado su labor intelectual al análisis de diversos temas relacionados con los estudios latinoamericanos, la teoría social y cultural, la violencia de Estado y sus secuelas, la teoría decolonial, el imperialismo, las humanidades ambientales, entre otros. Entre sus publicaciones más importantes se encuentran: Where Memory Dwells: Culture and State Violence in Chile (2009); con Herman Gray coeditó Towards a Sociology of the Trace (2010); The Extractive Zone: Social Ecologies and Decolonial Perspectives (2017) y Beyond the Pink Tide: Art and Politics in the Americas.

En The Extractive Zone, GómezBarris documenta lo que acontece en territorios específicos de Latinoamérica, donde el capital extractivista se expande de forma vertiginosa. En primer lugar, caracteriza los territorios donde opera el extractivismo con el término de "zona extractiva" (extractive zone) para referir el "paradigma colonial, una visión del mundo y de tecnologías que caracterizan a estas regiones como poseedoras de una 'alta biodiversidad' con el fin de reducir la vida a un recurso a ser capitalizado". ${ }^{2} \mathrm{La}$ autora confirma así que la economía global extractiva hunde sus raíces en la época colonial, la cual posicionó los recursos como el oro, la plata, el caucho, entre otros, en el mercado global. Esta dinámica se extiende hasta nuestros días, incluyendo los últimos ańos de la privatización neoliberal llevada a cabo por varios países de Latinoamérica. El objetivo de la obra es, sin embargo, analizar las ecologías sociales que subsisten dentro de la zona extractiva, en especial los movimientos sociales y artísticos que defienden la integridad de dichos territorios. El estudio ayuda a Gómez-Barris a conceptualizar, de mejor manera, las historias de conquista y colonización que han generado las zonas extractivas en diversos países de Latinoamérica a lo largo de la historia. Emplea una metodología "decolonial feminista queer", gracias a la cual identifica y analiza perspectivas críticas que emergen dentro de espacios mercantilizados, a los que denomina "perspectivas sumergidas".

La autora toma la imagen de un río, sobre el cual nuestra mirada se enfoca en su superficie, sin percibir todo el universo que existe debajo de sus aguas. Dentro de la zona extractiva

\footnotetext{
${ }^{2}$ Macarena Gómez-Barris, "Prefacio", The Extactive Zone. Social Ecologies and Decolonial Perspectives (Carolina del Norte: Duke University Press, 2017). Todas las referencias en adelante son traducciones propias
} 
persistirían ecologías sociales que resisten los embates de la economía global. Estas "perspectivas sumergidas" son caracterizadas por Gómez-Barris como "sistemas aleatorios, complejos y coordinados" 3 ilegibles para la lógica capitalista extractivista. Así, Gómez-Barris reconoce la existencia de estas perspectivas y las pone en valor al encontrar en ellas puntos de apoyo para nuevas lecturas de la problemática extractivista. A lo largo de su obra, desarrolla su investigación apoyada en estas perspectivas sumergidas, las cuales desafían y erosionan el imperativo monocultural de Occidente. En efecto, para la autora, las perspectivas sumergidas escapan del etnocentrismo, de la objetivación científica y de las tecnocracias extractivas que instalan campos petroleros, oleoductos, hidroeléctricas y mineras.

El primer caso de estudio se encuentra en la región del Yasuní, al este de Ecuador, considerado el territorio con mayor biodiversidad en el planeta. El Yasuní es una zona de la Amazonia ecuatoriana donde la inmensa biodiversidad rompe cualquier intento de catalogación de sus riquezas. Se ha visto amenazado por la instalación de la industria petrolera, que pone en peligro la biodiversidad del área. Sobre este entorno se instala una visión extractivista, en línea con las lógicas corporativas y estatales, que conciben

${ }^{3}$ Gómez-Barris, "Prefacio", The Extactive Zone. la tierra como una mercancía y no como un lugar donde la vida prolifera. La lógica extractivista, que busca mapear los territorios para volverlos zonas de explotación, choca con una naturaleza que la sobrepasa. A esto se suman los diversos movimientos sociales y las resistencias de los pueblos indígenas. La investigadora analiza en especial el movimiento YASunidos, nacido como protesta ante la negativa del gobierno ecuatoriano a ratificar el tratado Yasuní-ITT, por el cual se prohibía la licitación de los territorios del Yasuní a empresas extractivistas. Estas fuerzas, que emergen dentro de la zona extractiva, producen alternativas que contrarrestan la condición colonial. La resistencia ante el avance del extractivismo congrega, en torno al Yasuní, a diversas personas transfeministas, ecológicas y urbanas, que de manera coordinada con los afrodescendientes y los pueblos nativos proporcionan alternativas, a pesar de la impronta de la zona extractiva. La perspectiva sumergida dentro de este ámbito está dada por la fenomenología andina, que para la autora "describe la relación humana con las dimensiones sensuales, íntimas y corporales del mundo natural que vinculan la vitalidad de los ámbitos materiales e inmateriales". ${ }^{4} \mathrm{La}$ fenomenología andina "se desvía del cuerpo biológico individual para alcanzar el cuerpo de

\footnotetext{
${ }^{4}$ Gómez-Barris, The Extactive Zone, 48.
} 
montańas, ríos, piedras y el cuerpo terrestre de la Pachamama". 5 La relación entre el sujeto andino y su medio ambiente es de agradecimiento y respeto, pues se ve vinculado con éste. La experiencia con la tierra y la territorialidad escapa a los esquemas neoliberales, se vuelve una posibilidad de descolonización. ${ }^{6} \mathrm{Al}$ mismo tiempo, la autora analiza cómo, de manera sutil, el turismo espiritual deviene también en una zona extractiva, al ocupar terrenos sagrados y tomar esquemas culturales andinos para adecuarlos a una retórica New Age y traficar con ellos.

Gómez-Barris muestra también la situación de los territorios Mapuche, Pehuenche y Huilliche al sur de Chile, donde existe el esfuerzo del estado colonial por "eliminar a los nativos", 7 a quienes se les somete al terror debido al despliegue de fuerzas policiales en sus territorios. Las huelgas de hambre llevadas a cabo por grupos de mujeres indígenas han sido formas de disidencia y resistencia dentro de la zona extractiva. $\mathrm{Al}$ apoyarse también en el trabajo del cineasta Francisco Huichaqueo, la autora presenta otra perspectiva sumergida que, a partir de un lenguaje estético, desafía la mirada normativa colonial que criminaliza a los pueblos indígenas. $\mathrm{Al}$ romper con convenciones estéticas formales, Huichaqueo nos ayuda a visualizar y lamentar el

${ }^{5}$ Gómez-Barris, The Extactive Zone, 49.

${ }^{6}$ Gómez-Barris, The Extactive Zone, 14.

${ }^{7}$ Gómez-Barris, The Extactive Zone, 14. despojo territorial y la implantación violenta del pino y el eucalipto en perjuicio de otros árboles nativos. Así, a través del trabajo del cineasta, Gómez-Barris encuentra una perspectiva que desafía la ocupación, la violencia y la destrucción, erosionando así el imaginario extractivista.

La problemática que causan las centrales hidroeléctricas, tanto para la biodiversidad en los ríos como en los perjuicios sobre las comunidades nativas que ocupan estos territorios, es otro caso que la autora explora en la región del valle del Cauca, en Colombia. Para su análisis, Gómez-Barris se ayuda del trabajo fílmico de la artista colombiana Carolina Caycedo. Esta última emplea una técnica que consiste en enfocar de forma invertida, desde el fondo de las aguas de los ríos del valle, lo que acontece en éstos. La autora del libro percibe que, gracias a la técnica visual de Caycedo, emerge una mirada que eclosiona la visión extractivista. Así, "se desplaza la centralidad ocular del desarrollo humano para, en cambio, revelar una visualidad invertida, borrosa, sumergida, debajo de la superficie". ${ }^{8}$ Gómez-Barris denomina a esta perspectiva "epistemología de ojo de pez", la cual ofrece un orden de percepción que pone en valor la exuberante vida de los ríos del valle del Cauca, al mismo tiempo, muestra el desastre ecológico que origina una empresa hi-

${ }^{8}$ Gómez-Barris, The Extactive Zone, 15. 
droeléctrica. La artista muestra imágenes satelitales, usadas para identificar y clasificar nuevas zonas extractivas al servicio de la industria capitalista global, para darle nueva significación al mostrar estas geografías como fuentes de conocimiento locales y relaciones comunales.

Otra perspectiva sumergida proviene de la crítica anarquista feminista indígena defendida por diversos activismos antiextractivistas. La autora se centra en las historias producidas por mujeres indígenas aymaras, quienes históricamente han representado, a través de sus luchas, una resistencia frente a la impronta del capitalismo global. Presenta también distintos ejemplos de producción intelectual y cultural de organizaciones anarco-feministas, con especial foco en el trabajo realizado por la organización Mujeres Creando de Bolivia. Según Gómez-Barris: "los feminismos anarco-indígenas representan una forma de vida desde otro punto de vista que se opone, critica, hace visible y rehace la zona extractiva". ' Las diferentes experiencias comparten la historia de una ética anticapitalista que desmantela y rehace la posibilidad fuera de la minería, determinante en la economía de Bolivia dentro del mercado global desde el siglo Xv.

Finalmente, destaca que el trabajo de Gómez-Barris no se ha limitado sólo a un estudio teórico, ella misma ha pasado largos periodos de estadía en las zonas objeto de su estudio. De esta manera, desarrolla una crítica a los marcos disciplinarios que de manera sutil "sumergen" las fuerzas vitales que subsisten dentro de estas zonas. Las experiencias compartidas con activistas, artistas, y comunidades de Sudamérica le permiten dejarse permear por el contexto, ayudándole así, a elaborar su propia metodología para describir aquello que emerge y erosiona las matrices coloniales dentro de las zonas de extracción. La autora no arroja una mirada pesimista hacia el futuro, ni tampoco se queda en la mera descripción de las actividades de resistencia frente al extractivismo. Al contrario: su obra intenta aportar herramientas conceptuales para el mejor análisis de las dinámicas neocoloniales y contribuir así a la descolonización del imaginario extractivista. 